DOI: http://doi.org/10.21698/simi.2017.0026

\title{
A STUDY OF THE CONTENT IN VOLATILE OILS AND THEIR COMPOSITION OF VARIOUS AROMATIC HERBS FROM ECOLOGICAL SOILS
}

\author{
Mariana Popescu ${ }^{1,2}$, Diana Puiu ${ }^{1}$, Madalina Mihalache ${ }^{1}$, Natalita Bordei ${ }^{2}$, Anca Daniela Raiciu ${ }^{2, *}$, \\ Ionut Cristea ${ }^{1}$, Toma Galaon ${ }^{1}$, Luoana Florentina Pascu ${ }^{1}$ \\ ${ }^{1}$ National Research and Development Institute for Industrial Ecology ECOIND, 71-73 Drumul \\ Podu Dambovitei, 060652, Bucharest, Romania \\ ${ }^{2}$ S.C. HOFIGAL EXPORT-IMPORT S.A., 2 Intr. Serelor, 042124, Bucharest, Romania \\ ${ }^{*}$ Corresponding author: daniela_raiciu@yahoo.com
}

\begin{abstract}
Volatile oils (aromatic essences) have been well known since ancient times, both as food flavors and as a treatment solution for sanitary and cosmetic purposes.

In order to highlight the content in the volatile oils and their composition, a number of fresh aromatic plants have been studied, as: lavender (Lavandula angustifolia), rosemary (Rosmarinus officinalis), sage (Salvia officinalis), thyme (Thymus vulgaris) and oregano (Origanum vulgare), all originated from the organic crops of the Hofigal Company.

Essential oils were obtained by using the water vapor extraction technique, while for the identification of volatile oil components was used gas chromatography coupled with mass spectrometry (GC-MS).

The experimental results present the volatile oil content of the studied aromatic plants and also the important and specific chemical components of each volatile oil. Likewise, the soils used for plants growth have been analyzed for organochlorine content by using gas chromatography with electron capture detector (ECD). The concentration of these organic compounds is below the maximum allowable limit established by specific law (Order no. 756/1997) for soils of Romania.

These volatile oils from organic sources will be used as raw materials for obtaining food supplements and cosmetics products.
\end{abstract}

Keywords: aromatic plants, GC-MS chromatography, volatile oil

\section{Introduction}

Volatile oils, products of secondary plant metabolism, are mixes of several chemical compounds which are characterized by a fragrant scent and by therapeutic proprieties. Volatile oils can accumulate in all organs of the herbs, in varying amounts. These compounds can be found in roots, stems, leaves, flowers, fruits, seeds or in the bark of different plants. Usually the concentration of volatile oils in plants is very low (below $1 \%$ ), rarely could have values above $10-15 \%$ or more. The complex chemical composition of volatile oils (thousands of chemical compounds) is based on mono and sesquiterpene constituents, and aromatic compounds. Physical proprieties of essential oils are defined by volatility at ambient temperature, with a specific scent and a burning taste (European Pharmacopoeia 2017).

In order to highlight the volatile oils from fresh plant products, different extraction procedures are used as distillation and hydrodistillation, extraction with volatile 


\section{INTERNATIONAL SYMPOSIUM "THE ENVIRONMENT AND THE INDUSTRY", SIMI 2017, PROCEEDINGS BOOK}

nonpolar solvents, extraction with liquid or solid fats, extraction with supercritical fluids or pressing procedure (Topala \& Tataru 2016, Berechet 2015). Choosing the suitable extraction method is function of the amount of volatile oil from several parts of the plant, and of its physico-chemical proprieties. In the present study was applied hydrodistillation techniques, a widely used extraction method for an expected amount of volatile oils, while pressing procedure is used especially for plants with a high concentration of essential oils (for example, citric pericarp) (Aumeeruddy-Elalfi 2016). The objective of the study consists in the determination and evaluation of essential oil's chemical composition, which was obtained by hydrodistillation from medicinal plants, according with the European Pharmacopoeia and the Romanian Pharmacopoeia.

Due to its phytohormones content, volatile oils are real anti-wrinkle and seboregular treatments in cosmetic preparations, with a very high hydration and regeneration capacity (Aumeeruddy-Elalfi 2016,). Also, these compounds used in some diseases at a suitable dose, represent the fastest and most effective remedy for aroma and phyto-therapy (de Sousa 2015, Manea 2016). In order to maintain these medical applicability, it is necessary that the organic food and supplements come from unpolluted soils, which are untreated with chemical fertilizers, synthetic pesticides, stimulants and plant growth regulators. For these experiments, none of the plants were treated with synthetic chemical compounds. However, historical presence of some pesticides in soil increases the risk of contamination. For the safety of the results, were performed determinations of organochlorine pesticides from plant soils, within the Romanian law (Order 756/1997).

\section{Materials and Methods}

The selected plants for the actual reasearch (lavender, rosemary, sage, thyme and oregano) are provided from Hofigal Company ecologic crops, preserved and deposited according to standards requirements, then analyzed for volatile oils content and composition. Gravimetric analysis was used for essentialcuantification after steam extraction. Regarding the quality of the extracts, it was carried out a screening of samples in hexane by using gas chromatography mass spectrometry (GC-MS) equipment from Thermo Electron Corporation, type Focus GS with a DSQ II mass spectrometer detector and a chromatographic column of fused silica, $30 \mathrm{~m}$ in length, $0.25 \mathrm{~mm}$ internal diameter, having a Macrogol $20.000 \mathrm{R}$ as stationary phase and 0.25 $\mu \mathrm{m}$ film thickness. The chemical compounds present in the volatile oils were identified using a NIST spectra library. The various retention times for the same compound are given by different harvest moments and GC performances changes among the analysis.

The quality of soils used for studied plants growth was assessed by quantitative analysis of the presence of organochlorine pesticides. $10 \mathrm{~g}$ of each type of soil was extracted with hexane and analyzed by a gas chromatography Agilent 7890A, equipped with an electron capture detector and a 5\% phenyl-95\% dimethylpolysiloxane column, $60 \mathrm{~m}, 0.25 \mathrm{~mm}$ internal diameter and $0.25 \mu \mathrm{m}$ film thickness. The extraction method and performance parameters were accomplished as it is stated in EN ISO 10382/2007 for organochlorine pesticides. 


\section{Results and Discussion}

The quantity of volatile oils obtained by hydrodistillation extraction from studied herbs, expressed in $\mathrm{mL} / \mathrm{kg}$ dry matter, it is presented in the Fig. 1.

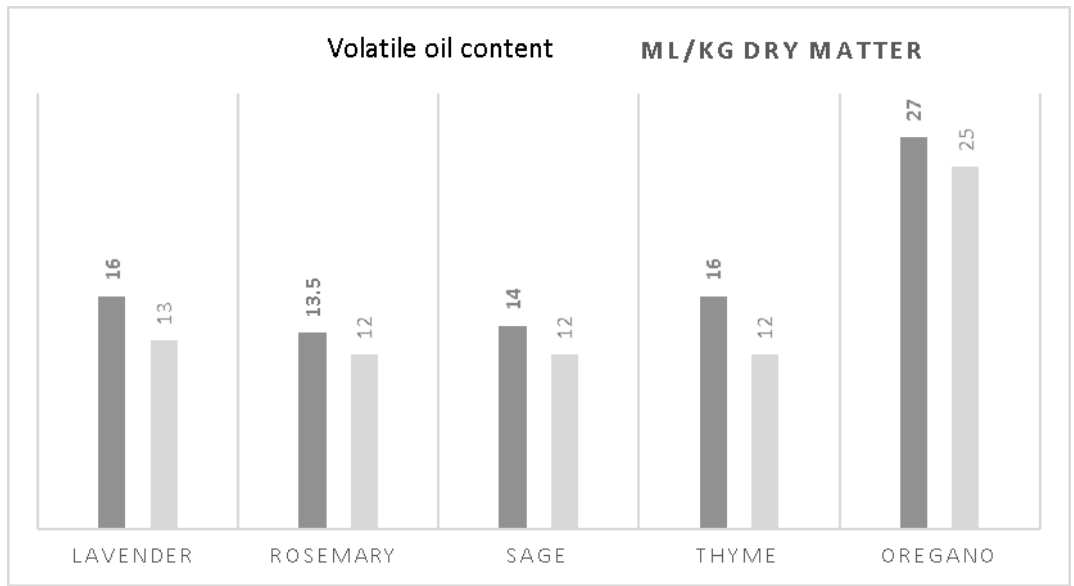

Figure 1. Content of volatile oil $[\mathrm{mL} / \mathrm{kg}]$ from fresh plants

All the obtained results correspond with the volatile oil quantities requested by the European Pharmacopoeia, edition in force, with near $10 \%$ higher than minimum amount: lavender (Lavandula angustifolia) minimum $13 \mathrm{~mL} / \mathrm{kg}$, rosemary (Rosmarinus officinalis) minimum $12 \mathrm{~mL} / \mathrm{kg}$, sage (Salvia officinalis) minimum 12 $\mathrm{mL} / \mathrm{kg}$, thyme (Thymus vulgaris) minimum $12 \mathrm{~mL} / \mathrm{kg}$ and oregano (Origanum vulgare) minimum $25 \mathrm{~mL} / \mathrm{kg}$. All the results are reported for dry matter of the samples.

The main compounds identified by using NIST library spectra, from the extracted volatile oils, are shown in the chromatograms from Fig. 2 and Tables 1-5.

Table 1. Chemical composition of volatile oil from lavender

\begin{tabular}{c|lcc}
\hline No. & \multicolumn{1}{|c}{ Name } & Retention time & Area \% \\
\hline 1 & Cineole & 13.63 & 2.3 \\
2 & a-Pinene & 15.43 & 6.0 \\
3 & 3-Carene & 16.08 & 1.7 \\
4 & Linalool & $\mathbf{2 5 . 2 4}$ & $\mathbf{3 4 . 6}$ \\
5 & Linalyl acetate & $\mathbf{2 5 . 4 5}$ & $\mathbf{3 7 . 8}$ \\
6 & Caryophylene & 26.22 & 3.8 \\
7 & a-Terpineol & 26.49 & 1.3 \\
8 & Lavandulol acetate & 26.69 & 3.5 \\
9 & a-Farnesene & 28.11 & 1.5 \\
10 & Terpineol & 28.78 & 2.9 \\
\hline
\end{tabular}

lavender and sage volatile oil, the compounds of interest (Table 1,3) are between the limits given by European Pharmacopoeia, respectively 20-45\% for linalool and 25- 
$46 \%$ for linalyl acetate in lavender oil, and $20-60 \%$ for thujone trans and cis isomers, $1-20 \%$ for camphor, in sage volatile oil. But for the other herbs, the limits were excedeed as: over $60 \%$ for thymol and carvacrol from oregano, over $13-21 \%$ camphor from volatile oil from rosemary and more than $28 \%$ for o-cymene in thyme volatile oil. The other compounds of interest (represented with bold text in Table 2,4,5) were below the given value.

Table 2. Chemical composition of volatile oil from rosemary

\begin{tabular}{c|lcc}
\hline No. & \multicolumn{1}{|c}{ Name } & Retention time & Area \% \\
\hline 1 & o-Pinene & $\mathbf{5 . 8 7}$ & $\mathbf{1 6 . 1}$ \\
2 & Camphene & 7.60 & 6.2 \\
3 & B-Pinene & 9.84 & 2.7 \\
4 & Limonene & 15.78 & 4.4 \\
5 & Cineole & $\mathbf{1 6 . 1 4}$ & $\mathbf{1 2 . 2}$ \\
6 & Camphor & $\mathbf{3 1 . 2 9}$ & $\mathbf{2 8 . 6}$ \\
7 & B-Linalool & 33.36 & 2.3 \\
8 & Caryophyllene & 34.64 & 4.7 \\
9 & Verbenone & 38.96 & 3.8 \\
10 & Borneol & 39.03 & 7.0 \\
\hline
\end{tabular}

Performing soil analysis, organochlorine pesticides as $\mathrm{HCH}$ isomers, heptachlor, heptachlor epoxide, aldrin, dieldrin, endrin, endosulfan were below the quantification limit of the method, $0.01 \mathrm{mg} / \mathrm{kg}$ dry matter, which is within the recommended alert limit value given by soil legislation (Order 756/1997). 
INTERNATIONAL SYMPOSIUM "THE ENVIRONMENT AND THE INDUSTRY", SIMI 2017, PROCEEDINGS BOOK

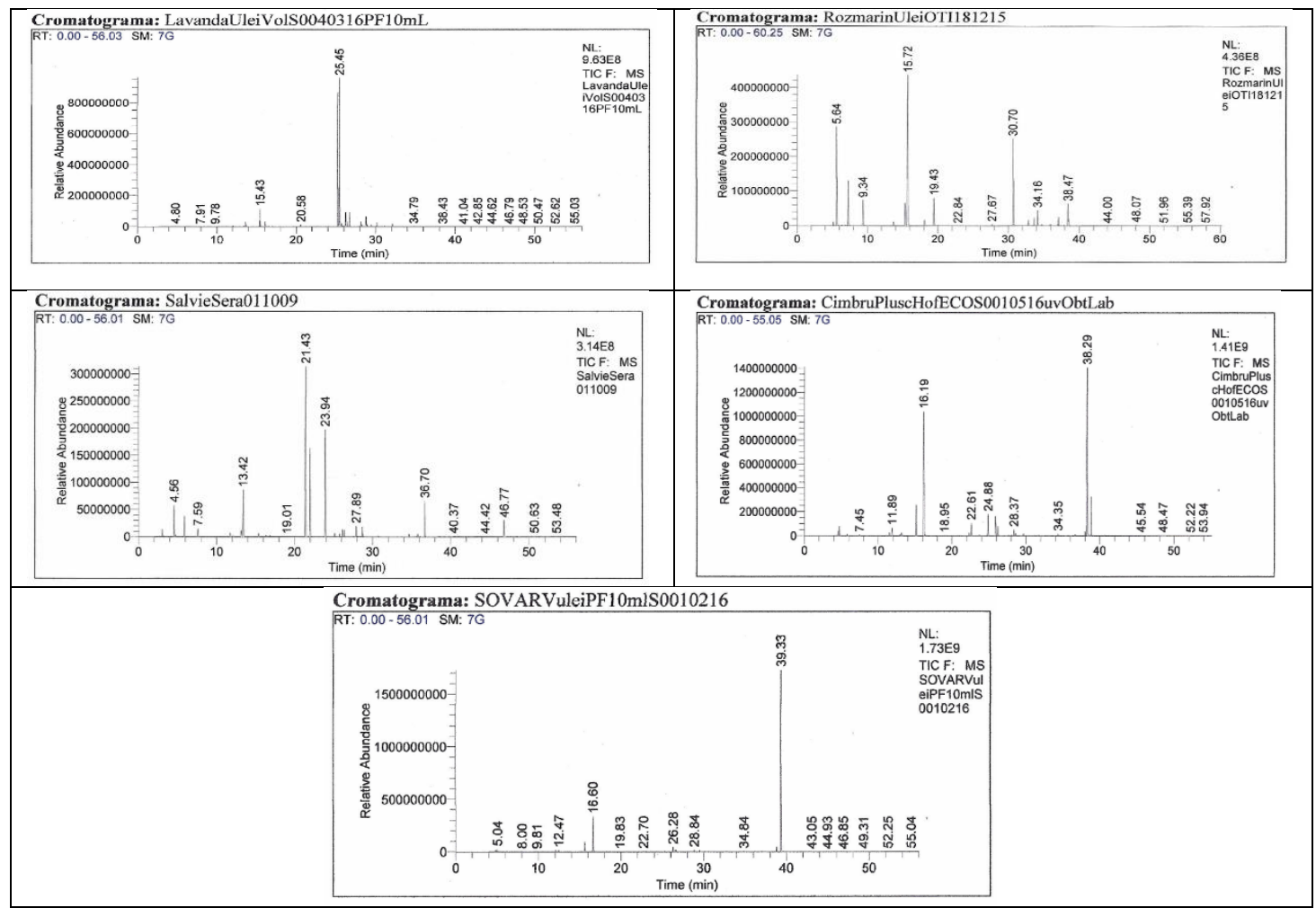

Figure 2. GC-MS chromatograms for studied volatile oils 
Table 3. Chemical composition of volatile oil from sage

\begin{tabular}{c|lcc}
\hline No. & \multicolumn{1}{|c}{ Name } & Retention time & Area \% \\
\hline 1 & a-Pinene & 4.55 & 4.9 \\
2 & Camphene & 5.87 & 4.1 \\
3 & B-Pinene & 7.59 & 2.0 \\
4 & Cineole & 13.13 & 1.5 \\
5 & Limonene & 13.42 & 10.5 \\
6 & Thujone trans & $\mathbf{2 1 . 4 3}$ & $\mathbf{3 4 . 6}$ \\
7 & Thujone cis & $\mathbf{2 1 . 9 8}$ & $\mathbf{1 3 . 1}$ \\
8 & Camphor & $\mathbf{2 3 . 9 3}$ & $\mathbf{1 6 . 0}$ \\
9 & Viridifloral & 36.70 & 4.5 \\
10 & Epimanool & 46.77 & 2.4 \\
\hline
\end{tabular}

Table 4. Chemical composition of volatile oil from thyme

\begin{tabular}{c|lcc}
\hline No. & \multicolumn{1}{|c}{ Name } & Retention time & Area \% \\
\hline 1 & Phellandrene & 4.73 & 1.6 \\
2 & 4-Carene & 11.89 & 2.1 \\
3 & Terpinene & 15.13 & 5.8 \\
4 & o-Cymene & $\mathbf{1 6 . 1 8}$ & $\mathbf{3 2 . 5}$ \\
5 & Terpineol & 22.61 & 1.9 \\
6 & Linalool & 24.88 & 3.2 \\
7 & Caryophyllene & 25.86 & 4.4 \\
8 & Thymol methyl ether & 26.18 & 1.8 \\
9 & Thymol & $\mathbf{3 8 . 2 8}$ & $\mathbf{3 7 . 0}$ \\
10 & Carvacrol & $\mathbf{3 8 . 8 0}$ & $\mathbf{5 . 0}$ \\
\hline
\end{tabular}

Table 5. Chemical composition of volatile oil from oregano

\begin{tabular}{c|lcc}
\hline No. & \multicolumn{1}{|c}{ Name } & Retention time & Area \% \\
\hline 1 & a-Pinene & 4.84 & 0.9 \\
2 & Phellandrene & 5.04 & 1.3 \\
3 & Myrcene & 12.10 & 1.4 \\
4 & Carene & 12.47 & 1.1 \\
5 & $\gamma$-Terpinene & 15.61 & 4.8 \\
6 & m-Cymene & 16.60 & 14.5 \\
7 & Caryophyllene & 26.28 & 1.6 \\
8 & Borneol & 28.84 & 0.9 \\
9 & Thymol & $\mathbf{3 8 . 8 2}$ & $\mathbf{1 . 7}$ \\
10 & Carvacrol & $\mathbf{3 9 . 3 3}$ & $\mathbf{6 9 . 7}$ \\
\hline
\end{tabular}

\section{Conclusions}

The quantity of volatile oil obtained through hydrodistillation from studied herbs: lavender (Lavandula angustifolia), rosemary (Rosmarinus officinalis), sage (Salvia officinalis), thyme (Thymus vulgaris) and oregano (Origanum vulgare), and the main 
compounds identified through GC-MS from each essential oil sample are appropriate to the values given by European Pharmacopoeia, edition in force. The soil free of organochlorine pesticides was suitable for medicinal plants growth. As a result, the volatile oils from studied plants can be used to obtain organic food and cosmetics.

\section{References}

Aumeeruddy-Elalfi, Z, Gurib-Fakim, A \& Fawzi Mahomoodally, M 2016, 'Chemical composition, antimicrobial and antibiotic potentiating activity of essential oils from 10 tropical medicinal plants from mauritius', Journal of Herbal Medicine, vol. 6 , no. 2 , pp. 88-95.

Berechet, M D, Calinescu, I, Stelescu, M D, Manaila, E, Craciun, G, Purcareanu, B, Mihaiescu, D E, Rosca, S, Fudulu, A, Niculescu-Aron, I G \& Mihai, R 2015, 'Composition of the Essential Oil of Rosa Damascena Mill. Cultivated in Romania', Revista de chimie (Bucharest), vol. 66, no. 12, pp. 1986-1991.

European Pharmacopoeia 2017, Council of Europe, the 9th edition, Vol. 1.

Manea, S, Tamas, V, Carabela, V, Dima, A \& Luntraru, C 2016, 'Range of cosmetics based on natural extracts with role of protection against environmental pollution factors', International Symposium "The Environment and the Industry", SIMI 2016, National Research and Development Institute for Industrial Ecology, pp. $173-178$

Order 756 of Nov 3, 1997, on the reglementation of assessing the environmental pollution, issued by the Minister of Water, Forest and Environment, no. 303.

de Sousa, D P, de Almeida Soares Hocayen, P, Andrade, L N \& Andreatini, R 2015, A systematic review of the anxiolytic-like effects of essential oils in animal models', Molecules, vol. 20, no. 10, pp. 18620-18660.

Topala, C M \& Tataru, L D 2016, 'Atr-ftir study of thyme and rosemary oils extracted by supercritical carbon dioxide', Revista de Chimie (Bucharest), vol. 67, no. 5, pp. 842 . 